\title{
The genetically modified foods debate: demystifying the controversy through analytical chemistry
}

\author{
Sylvia Daunert • Sapna Deo • Xenia Morin • Aldo Roda
}

Published online: 16 August 2008

(C) Springer-Verlag 2008

The genetic manipulation of foods, including plants and animals, has been pursued for hundreds of years. It could be argued that Gregor Mendel was already performing genetic manipulation in the 19th century. As early as in 1885, Mendel presented his first paper entitled "Experiments on Plant Genetic Hybridization", which he published in 1886 in the Proceedings of the Natural History Society of Brünn. While Mendel's work was then overlooked and even criticized, it is now considered a cornerstone of modern genetics and genetic manipulation. It was not until the early 20th century that Mendel's work was taken seriously, and his experiments reproduced and further expanded by an array of notable geneticists and evolutionary biologists. Arguably, so-called selective breeding is a result of Mendel's initial work. Selective breeding has been used to create fruits of exotic taste, roses with specific colors and fragrances, and chicken that lay eggs that are lower in cholesterol content. This technique is limited to endowing

\section{S. Daunert $(\square)$}

Department of Chemistry and Department of

Pharmaceutical Sciences, University of Kentucky,

Lexington, KY 40506-0055, USA

e-mail: daunert@uky.edu

\section{S. Deo}

Department of Chemistry \& Chemical Biology,

Indiana University Purdue University Indianapolis,

LD326 Blackford Street,

Indianapolis, IN 46202, USA

\section{Morin}

Princeton Writing Program and the Princeton Environmental Institute, South Baker Hall, Whitman College,

Princeton University,

Princeton, NJ 08544, USA

\section{A. Roda}

Department of Pharmaceutical Sciences,

Alma Mater Studiorum-University of Bologna,

Via Belmeloro 6,

40126 Bologna, Italy or enhancing one particular species with a trait that is native to the same species. There is no inter-species crossing, and, thus, it is viewed by most as harmless genetic manipulation. The advent of biotechnology allowed genetic modification and "selective breeding" to become more precise genetic manipulation through the introduction of specific genes that were not indigenous to the species. New traits could be introduced into already elite varieties to produce enhanced properties. Inter-species crossing has enhanced traditional crops by breeding of insect-resistant and increased nutritional value corn and rice, respectively. Much controversy has followed this species modification and subsequent creation of genetically modified foods. Proponents of GM foods highlight the potential humanitarian ramifications of GM crops proliferation placing emphasis upon the increased nutrition and heartiness of the crops, in relation to combating malnutrition and world hunger. The proponents of genetically modified foods engage in the advantages that they provide with regard to nutrition and help in the fight to end human malnutrition and hunger. The opponents, on the contrary, cite the fact that allergies and inter-species gene transfer may be hazardous to human health.

The GM foods debate is global, impacting all societies regardless of their socioeconomic status. The potential impact on the poor and in ending human hunger is especially important and may outweigh some concerns imposed by the detractors of these foods. Major concerns of those who oppose genetically modified (GM) foods include the risk of allergenicity in humans and the potential negative environmental effects of modified crops. Although GM foods are extensively tested for the risk of allergenicity, cases of allergenicity - such as GM peas in mice - have received much publicity. GM peas were never introduced to the public sector, yet this case has been touted by opponents of GM foods as a prime example of their potential hazards to human health. Another issue that has been widely publicized is the possible transfer of antibiotic resistant genes from GM foods to the microflora housed in 
human intestines. Evidently, if such a speculation were true, the consequences of GM foods consumption could be disastrous to human health. However, this inference is pure speculation and no evidence of such gene transfer has ever been recorded. There are studies that have looked at this possibility, and concluded that-based on known mechanisms - it is unlikely that this scenario could occur, or, furthermore, that it would have detrimental effects. A valid argument made by GM foods opponents refers to the fact that little is known about the long-term effects of GM crops on the environment, microorganisms, animals, and humans. For example, will Darwinian evolution demonstrate that insects can evolve to successfully combat the current insect-resistant GM crops? The answer to this question remains unknown. As a precaution, non-GM crops are not grown near GM crops. In a similar vein, GM opponents are also concerned that these crops could present a threat to biodiversity, with plantproduced pesticides harming other organisms and crops, thus, leading to a decreased variety of natural foods. The possibility of gene transfer from GM crops to conventional crops grown in the same locations can threaten food safety and contamination. Moreover, an additional major concern is the spread of herbicide-resistant genes to unintended weeds that would create so-called 'super-weed' that will be difficult to control.

An economic concern arises from the great corporate presence in GM food production. The dominance of these multinational agrochemical corporations (i.e., Monsanto, Syngenta, and DuPont-Pioneer) is an issue of concern to activist groups such as Greenpeace for fear that farmers growing GM crops will become dependent on these companies. Even more activists oppose GM foods on philosophical ideals as opposed to scientific or economic principles. These groups argue that genetic tampering with nature by mixing genes is unethical and a violation of the intrinsic values of natural organisms. On another more practical consumer-related note, a struggle that opponents of GM foods bring up is the proper labeling of those GM foods that reach the market.

Opponents of GM foods include the aforementioned special interest groups (e.g., Greenpeace, Friends of Earth, and the Organic Consumers Association), and public figures, including His Royal Highness The Prince of Wales; supporters of GM technology include many plant scientists, Nobel Laureate Norman Borlaugh (the father of GM crops and a leader in this scientific field), and notable individuals such as former British Prime Minister Tony Blair, President Jimmy Carter, and Indian Prime Minister Dr Manmohan Singh.

While concerns regarding genetic modification exist, GM crops offer a potentially tremendous benefit to society. Agriculture is already becoming more efficient with the use of GM technology, as it gives farmers more control over the range of crops that can be produced in a cost-effective manner. The use of insect-resistant crops reduces the use of dangerous chemical pesticides, enabling both cost-effective farming and reduction of the ill effects of pesticides on our environment. The argument stressing that there is currently enough food in the world to feed everyone is not valid since, indeed, rising population growth is inducing a strain on global food availability. This strain on food reserves is made worse by population growth, which itself is steadily increasing, with an estimated 2 billion more people worldwide by the year 2050 . GM crops provide immunity to insect attack on stored grain, and eliminate the need for expensive pesticides; these properties address some of the major concerns of food shortages in poor countries. An increase in food production due to GM crop proliferation should make food cheaper according to the laws of supply and demand. The potential advances made in GM crops will allow production of food with unique benefits such as food fortified with vitamins and nutrients, food with long shelf-life, and perhaps even food that intrinsically produces life-saving vaccines. Moreover, GM crops could be designed to tolerate drought conditions, extreme temperatures, and/or salinity conditions. Forthcoming technological advances should allow for higher crop yields, foods of better quality, and cheaper overall food production.

Clearly, the GM foods debate has no foreseeable resolution in the near future. There may not be an absolutely clear or unilateral answer to this debate, but we, as analytical chemists, can make a significant contribution to this problem. There is no question that more methods to allow rapid, sensitive, and accurate measurements of genetically modified organisms (GMOs) in food and feed are required, and methods that can distinguish amongst different species of GMOs. Emphasis must be placed on adapting current analytical methods and designing new ones capable of costeffective detection of transgenic DNA, and of newly produced proteins. These methods should be able to perform analysis in untreated and processed food. An important concern that must be addressed is the ability to detect unapproved GMOs that are accidentally released in foods or feed. In many cases, the presence of these organisms in foods can be minimal, but, nevertheless, they should be detectable. Thus, a host of sampling strategies directed to detecting the presence of GMOs in foods in a sensitive, selective, and reliable manner should be developed and employed. In addition, we cannot neglect the question of potential allergenicity of GM foods. To that end, analytical chemists can contribute to easing the concerns of consumers to GM foods by developing reliable analytical methods for the rapid testing of possible allergenicity. This is, indeed, an important area of research that needs more attention. We should not forget that proteins not known to be allergic in the species of origin can become allergenic when transferred to a different species, as observed in the aforementioned case of GM 
peas. Therefore, scientists cannot assume that GM foods are safe for human consumption just by merely following the premise that target modified proteins are harmless to other animals. The determination of allergenicity will require the design of a battery of methods that are highly selective and sensitive for the species that intends to consume the target GM food. Validation of existing commercial and research methods that have been used in other applications and that can be adapted for GM food detection is a critical area of analytical work that needs to be emphasized. While the literature describing new assay methods for GM foods is steadily increasing, the need for accurate and selective quantitation of all approved and newly developed GMOs in a variety of matrices is still pending. A 2004 National Academies of Sciences report also lists important areas for development (http://www. nap.edu/openbook.php?isbn=0309092094). Analytical chemists are uniquely qualified to provide solutions to the GM foods problem and, thus, have an opportunity to make an impact in the future of society by demystifying some of the fears and misconceptions the general public may have toward GM foods.

In this special issue of Analytical and Bioanalytical Chemistry, we have chosen to highlight advances in the field of GM food analysis. Articles in this special issue focus on the analytical and biochemical tools available. These methods range from molecular methods, to PCR-based detection, to more traditional immunoassay techniques. One feature article describes the potential allergenicity issues of GM food and the current regulations for testing of allergenicity. Another gives an exciting overview of the field of GM foods, and focuses on the on-going debate on the use and consumption of these crops.

In 2003, The New York Times published an eloquent piece describing the struggle that poor nations face when trying to develop improved versions of local crops. There are a handful of biotechnology companies that own the patents and rights to the technologies needed to genetically modify these crops and - by not sharing them with these impoverished nations - are currently hindering local farmers. This same article states “... the world shouldn't ban genetically modified food. It should develop a cassava root resistant to the mealy bug and drought-proof corn. Antiglobalization activists are right that corporate greed is the problem. But they are wrong that genetically modified crops should be banned. The real crime of genetic modification is not its risks but that it is squandering its promise, widening the gap between rich and poor." We concur with this statement and hope that this issue increases the interest and appetite of analytical chemists in getting involved in the development of new methods to help ensure the safety of genetically modified foods. If so, our mission as editors will be accomplished!
P.S. The GM foods debate is such an emotional one that even rap songs have been released in support of this technology. Our favorite pays tribute to Nobel Laureate Norman Borlaug, and widely considered the father of the Green Revolution. The lyrics of the rap song below are a clear example of the far-reaching GM food debate, and highlights the history and potential benefits of GM technology.

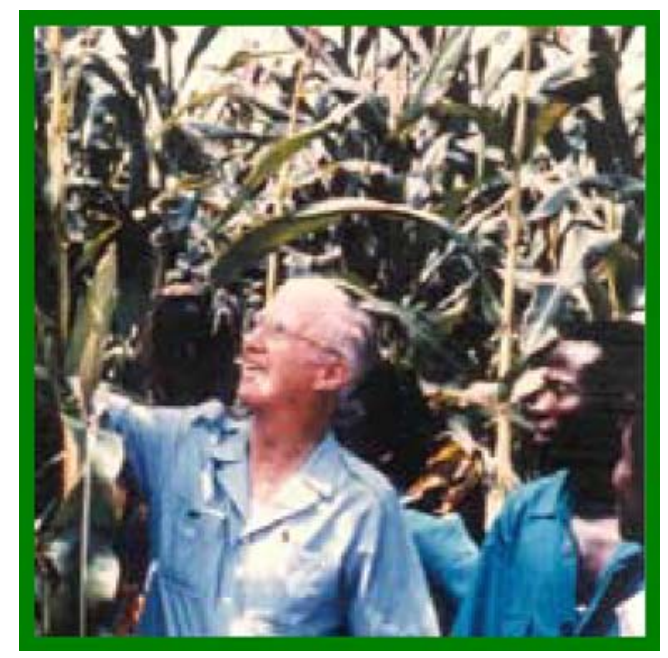

The Norman Borlaug Rap (Thank you, Norman) for downloading of the song: http://www.agbioworld.org/ biotech-info/topics/borlaug/borlaug-rap.html

\section{I don't know what you been told about farming and food in days of old, but listen and take this to the bank: If there's food in your tummy then you'd better thank}

N-O-R-M-A-N Norman Borlaug, thank you, man

Straight out of Iowa Norman came, then traveled the world, saw suffering and pain. Millions of people were starving, yo in Pakistan, India, Mexico.

But just a few years after Norman came, they all had bumper crops of grain.

Norman found the great solution, known as the Green Revolution. Billions of people are alive today because of work done by the man named

\section{Norman}

\section{CHORUS:}

Norman Borlaug, you may be the greatest man in history. Using science and your brain to stamp out hunger, woe and pain. 
Creating new varieties

of plants with new technologies.

You're the man we look up to.

That is why we're thanking you.

But then some people started to panic, telling the farmers to go organic.

Technophobes started making a mess of Norman Borlaug's great success.

Green groups thought they found the cure in stinky piles of cow manure, telling their governments not to send fertilizer aid to our African friends.

So Norman came back to defend high-yield agriculture with his friend, Jimmy Carter, ex-president, to help all the African residents.

\section{CHORUS}

Norman and Jimmy hopped in a plane to help the Africans grow more grain. Soon the men were able to triple corn yields that the Greens had crippled.

Feeding the planet is his game and yet he does not have much fame. Got the highest scientific acclaim, and now you better know his name is

\section{Norman}

And he's still working in the fields, helping the farmers increase their yields. With fertilizer, water and better plant breeding he's making sure that farmers are feeding children and their families with corn and rice, cassava and peas.

The man has saved so many lives.

That's why they gave the Nobel Prize to

Norman

If you don't know, You better ask somebody About Norman

Norman Borlaug

Father of the Green Revolution

Nobel Peace Prize Winner

Forgotten Benefactor of Humanity

Adapted from: http://www.agbioworld.org
Readers interested in GM Foods are referred to:

W. Dong, L. Yang, K. Shen, B. Kim, G. A. Kleter, H. J. P. Marvin, R. Guo, W. Liang, and D. Zhang, GMDD: a database of GMO detection method, BMC Bioinformatics 2008, 9, 260-2698, http://www.biomedcentral.com/1471$2105 / 9 / 260$

http://www.forbes.com/business/2008/06/05/food-geneticsagriculture-biz-cx_0606oxford.html

http://query.nytimes.com/gst/fullpage.html?res=9E05E2 DB103FF930A25753C1A9659C8B63

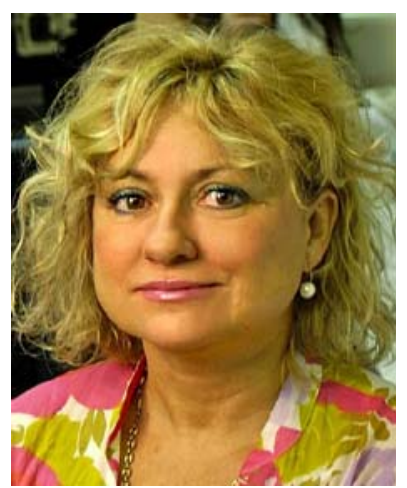

Sylvia Daunert

is the Gill Eminent Professor of Analytical and Biological Chemistry, the 2004-2005 Distinguished Professor from the College of Arts and Sciences at the University of Kentucky, and a 20052006 University of Kentucky Research Professor. Her research interests are in bioanalytical chemistry, at the interface between analytical chemistry, molecular biology, and bioengineering. More specifically, her group uses recombinant DNA technology to design new molecular diagnostic tools and biosensors based on genetically engineered proteins and cells for biomedical and environmental applications. Additionally, the research of her group focuses on the design of sensing arrays for the detection of molecules in small volumes and microfluidic platforms, and in the development of smart biomaterials for responsive drug-delivery systems. Dr Daunert has served as Editor of Analytical and Bioanalytical Chemistry since its inception in 2001.

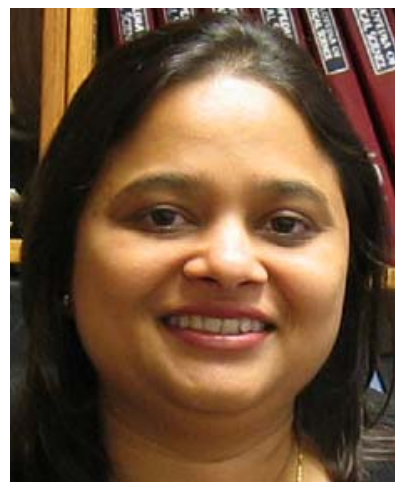

\section{Sapna Deo}

has been an Assistant Professor of Bioanalytical Chemistry in the Department of Chemistry and Chemical Biology at the Indiana University-Purdue University Indianapolis since 2005. She is author and co-author of over 55 scientific publications and several patents. Dr Deo is an editor of the book Photoproteins in Bioanalysis. Her research interest is in the development of novel bioanalytical techniques for detection of microRNAs and RNA molecules based on luminescence detection for application in diagnosis and pathogen detection. Other areas of research interest in Dr Deo's laboratory include the development of molecular probes for biosensing and bioimaging applications. Dr Deo's research is funded by the National Science Foundation and the National institutes of Health. 


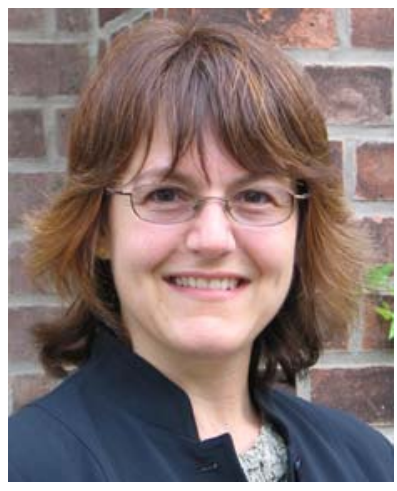

\section{Xenia Morin}

is a plant biochemist by training and currently holds the position of lecturer in the Princeton Writing Program and the Princeton Environmental Institute at Princeton University. She is interested in the interplay between science, technology, and society, particularly in terms of agriculture and food production. She is concerned with a range of issues, from the acceptance of genetically modified foods to the emergence of the organic, local, and slow food movements. She also explores issues such as how to feed the world, food security, hunger and malnutrition, environmentalism and sustainability in agriculture, and the production of biofuels.

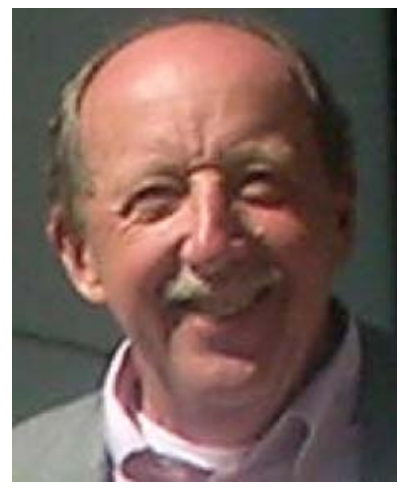

Aldo Roda

is Professor of Analytical Chemistry at Bologna University. His main research interests include the development of ultrasensitive biochemiluminescence imaging techniques for the localization of target molecules (proteins, nucleic acids) in biological samples, such as cells and tissues. 